\title{
Field Evaluation of Microencapsulated Phase Change Material Slurry in Ground Source Heat Pump Systems
}

\author{
Minsuk Kong ${ }^{1}$, Jorge L. Alvarado ${ }^{2, *}$, Curt Thies ${ }^{3}$, Sean Morefield ${ }^{4}$, Charles P. \\ $\operatorname{Marsh}^{4,5}$ \\ ${ }^{1}$ Department of Mechanical Engineering, Texas A\&M University, College Station, Texas, \\ 77843, USA, mskong1223@tamu.edu \\ ${ }^{2}$ Department of Engineering Technology and Industrial Distribution, Texas A\&M \\ University, College Station, Texas, 77843, USA, jorge.alvarado@tamu.edu \\ ${ }^{3}$ Thies Technology, Inc., Henderson, Nevada, 89014, USA, thiesman@aol.com \\ ${ }^{4}$ Construction Engineering Research Laboratory, US Army Engineering Research and \\ Development Center, Champaign, IL 61822, USA, Sean.Morefield@ usace.army.mil \\ ${ }^{5}$ Nuclear Plasma and Radiological Engineering at the University of Illinois at Urbana- \\ Champaign, USA, Charles.P.Marsh@usace.army.mil
}

\begin{abstract}
Microencapsulated phase change material (MPCM) slurries were field-tested in ground source heat pump (GSHP) systems in the Southern United States to validate their thermal performance and durability as heat transfer fluids (HTF). MPCM particles consisted of methyl stearate (melting temperature: $39.5{ }^{\circ} \mathrm{C}$ ) as phase change material (PCM), microencapsulated with polyurea shell. Experimental results showed that MPCM slurries transport more thermal energy than water at a constant pumping power due to the higher heat capacity associated with the PCM. Demonstration experiments showed that using MPCM slurries improved the heat load-to-pumping power ratio by up to $34 \%$ when using a coaxial heat exchanger. The coefficient of performance of the GSHP system was enhanced by up to $4.9 \%$ when using MPCM slurries. It can be concluded that MPCM slurries are viable HTF because of their higher heat capacity. In terms of durability, no
\end{abstract}

* Corresponding Author. Tel.: +1 979458 1900; fax: +1 9798627969.

Email address: jorge.alvarado@ tamu.edu (J.L. Alvarado) 
significant damage of MPCM was detected under continuous pumping conditions after 123,252 pump-cycles or an estimated life span of 10.5 years. Results also suggest that progressive cavity pumps are more suitable than centrifugal pumps from the durability point of view. Long-term durability studies should be considered for the eventual implementation of MPCM technology in heating and cooling applications.

Keywords: Microencapsulated phase change material (MPCM); Ground Source Heat Pump Systems; Heat Load-to-Pumping Power Ratio; Coefficient of Performance (COP); Durability

\section{Introduction}

With the development of the human society, energy consumption and environmental pollution have been issued over the world. Use of renewable energy sources has gained more attention as possible solutions for energy saving and environmental conservation. Among the various advanced energy systems using renewable energy sources, ground source heat pump (GSHP) systems have become more attractive for the thermal management of the commercial and residential buildings because of their high energy efficiency and sustainability [1-3]. The GSHP system basically contains a ground loop, where a heat transfer fluid (HTF) passes to absorb thermal energy from the surrounding ground. Since the subsurface temperature is not subject to large variations, the GSHP systems can provide constant heating and cooling energy with a high coefficient of performance (COP) [4]. Even though the GSHP systems need larger initial investment and maintenance cost, their environmental friendliness is significant enough to make them cost-effective. A number of studies have been 
performed to evaluate the performance of GSHP systems and applied the various types of ground heat exchangers to enhance the heat transfer performance and reduce the initial investment [5-10]. However, these systems still require large amount of a HTF to satisfy the heating and cooling demands. Pumping energy associated with handling these fluids is costly, so it is appropriate to consider ways to reduce the volume or pumping cost of HTFs needed for thermal management.

The use of microencapsulated phase change material (MPCM) slurry can be effective in improving the thermal performance of heat transfer systems through its high heat capacity enhanced by the phase change material (PCM) that undergoes phase change. Increased heat transfer performance can reduce the required flow rate of HTFs and consequently save energy through decreased pumping power. Many studies have been carried out for a fundamental understanding about the thermal properties, flow and heat transfer characteristics of MPCM slurries. In terms of thermophysical properties of MPCM slurries, adding MPCM particles to carrier fluid increased the apparent viscosity $[11,12]$. Apparent viscosity of MPCM slurry at low mass fraction was independent of shear rate, which indicates that MPCM slurry behaved like a Newtonian fluid [12, 13]. With respect to the stability of MPCM, microcapsules containing organic PCMs have shown good thermal stability in heating and cooling applications [14-16], even though their thermal physicochemical properties were slightly degraded after several thermal cycles $[16,17]$ due to the partial degradation of microcapsules by breakage [18]. Small MPCM particles $(2-10 \mu \mathrm{m})$ resisted continuous pumping conditions without any breakage $[19,20]$ after examining the capsules using a microscope, and measuring and contrasting the thermal properties of used MPCM slurries with fresh samples. The increase of the 
shell thickness decreased the breakage of microcapsules [21, 22] but it also led to lower amount of PCM and lower heat capacity [23]. With respect to pressure drop characteristics, mass fraction of MPCM in the slurry increased pressure drop, which was greater than that of carrier fluid due to the increased viscosity [23, 24]. Friction factor curve of MPCM slurry flowing through a straight tube fitted well with the correlation used for a homogeneous Newtonian fluid [12, 20]. Pressure drop of MPCM slurry was lower than that of carrier fluid at certain conditions due to a drag-reducing effect $[11,19]$. In terms of heat transfer characteristics, MPCM slurry could considerably enhance the heat capacity when compared to water due to the latent heat of fusion of PCM [24, 25]. Heat transfer coefficient of MPCM slurry significantly increased during the phase change process $[19,20,25,26]$. Average heat transfer coefficient of MPCM slurry was typically lower than that of water at a constant fluid velocity condition $[20,23,26]$.

Even though MPCM technology has been studied for the past two decades, MPCM slurries have not been widely implemented in commercial heating and cooling systems including the GSHP systems due to the lack of long-term reliable data of MPCM slurry. In the study, MPCM slurry was tested under laboratory conditions to see the enhancement of the overall performance of the coil heat exchanger (CHX) before employing it to commercial GSHP systems. In addition, field tests were conducted to evaluate the effect of using MPCM slurries as a HTF on the thermal performance of the GSHP systems for the cooling mode, which were installed in the Southern United States. The durability of MPCM particles was also examined to determine if they can resist continuous pumping conditions, which is significantly important for the implementation of MPCM slurries in the widespread industrial applications. 


\section{Experimental Setup}

\subsection{Lab-based Experimental Setup}

An experimental setup for the laboratory experiments was built to investigate the benefits of using MPCM slurry in a CHX, before testing the fluids in the field. The CHX used in the lab was same type of heat exchanger used in the field. A schematic diagram of the experimental setup is shown in Fig. 1. The experimental system mainly consists of two coil heat exchangers (HX01 and HX02), an air-cooled water chiller, a heater tank, pumps (P01 and P02), and a sampling station (SS01). The test section was fully instrumented with a differential pressure transducers (PT01 and PT02), thermocouples (TC01 TC08), and flow meters (FM01 FM03). The hot water from the heater tank was circulated through the annulus of the $\mathrm{CHX}$ (HX02) to heat the MPCM slurry until complete melting was achieved. The cold water pumped by the chiller was circulated through the annulus of the CHX (HX01) to cool the MPCM slurry until the phase change material crystallized. The MPCM slurry delivered by the centrifugal pump (P01) was circulated through the inner tube of both heat exchangers. Pressure drop and heat transfer rate of MPCM slurry were determined using the first $\mathrm{CHX}$ (HX01). For comparison purposes, the experiments using water were performed under the same flow rate and temperature conditions as with the MPCM slurry.

Fig. 1. Schematic diagram of experimental setup 


\subsection{Field-based Experimental Setup}

A ground source heat pump (GSHP) system installed in Texas, United States was selected for field testing, which is used mainly for cooling purposes. The GSHP system includes 108 wells of $25.4 \mathrm{~mm}$ bore holes with a depth of $91.4 \mathrm{~m}$. Water is circulated from the ground into the 26 heat pump units inside buildings using a large centrifugal pump, as shown in Fig. 2. Temperature of existing HTF (water) flowing through the GSHP system ranged from $33{ }^{\circ} \mathrm{C}$ to $44{ }^{\circ} \mathrm{C}$, which was taken into account to determine the melting point of the corresponding phase change materials. The phase change temperature of the PCM should be within the abovementioned temperature range to take full advantage of the effects of the PCM.

Fig. 2. Flow diagram of a heat transfer loop in the field

Using MPCM slurries in the whole loop of the GSHP system posed potential risks, including capsule breakage, which could lead to the formation of large agglomerates of phase change material and potential clogging of the whole GSHP system as reported by a previous study [27]. To avoid such a problem, one of heat pump units was isolated from the whole GSHP system by using a new coil heat exchanger (CHX). The CHX used in the field tests has inner and outer tubes, which are made of copper. The inner tube is corrugated to enhance heat transfer performance and the hydraulic diameter is $25.4 \mathrm{~mm}$ based on the cross sectional area and wetted perimeter of the tube. The diameter of outer tube is $38.1 \mathrm{~mm}$ and the curvature diameter of the $\mathrm{CHX}$ is $0.42 \mathrm{~m}$ with a total length of $6.4 \mathrm{~m}$. An instrumented heat transfer system with a new heat exchanger $(\mathrm{CHX})$ and pump 
were installed in between the heat pump and the ground water loop to investigate the effect of MPCM slurry on the thermal performance of the individual heat pump unit, as shown in Fig. 3. The fully instrumented heat transfer loop used for field testing mainly consisted of a MPCM slurry loop and a ground water loop. MPCM slurry delivered by a centrifugal pump or a progressive pump (P1) was circulated through the coil heat exchanger (HX1) and the heat exchanger of the heat pump to ensure a complete phase transformation of PCM. The melting process of phase change material took place when MPCM slurry flowed through the condensing unit of the heat pump, absorbing heat from the refrigerant. Ground water was circulated through HX1 to cool the MPCM slurry. Flow rate, pressure drop, and fluid temperature data needed for analysis were measured by using two flow meters (FM1 and FM2), two differential pressure transducers (DPT1 and DPT2), and six thermocouples (TC1 TC6), respectively. A sampling station (SS1) was designed and built to take samples, which were collected to determine the thermophysical properties of MPCM slurries. A data acquisition (DAQ) system was designed to monitor and record the data needed for the data analysis. National Instruments module was used to read voltage and current values using a voltage differential probe and a current transducer, respectively, which were used for calculating electrical power consumption of the pump and the heat pump. In addition, an Agilent data logger was used to read the flow rate, pressure drop, and temperature data. Specifications of the components in the experimental set-up are shown in Table 1.

Fig. 3. Flow diagram of a fully instrumented heat transfer loop 


\section{Table 1. Specifications of the components}

\section{Data Analysis}

The heat transfer rate was calculated by using the following equation.

$$
\dot{Q}=\dot{m} \cdot c_{p} \cdot\left(T_{\text {out }}-T_{\text {in }}\right)
$$

where $\dot{m}, c_{p}, T_{\text {in }}$, and $T_{\text {out }}$ are mass flow rate, specific heat of the fluid, inlet and outlet fluid temperatures of the heat exchanger, respectively.

Specific heat of the MPCM slurry is a function of the mass and the latent heat of fusion of the PCM, which is defined as the effective specific heat. The effective specific heat was determined by using the following equation.

$$
c_{p, e f f}=\frac{\dot{Q}}{\dot{m}_{M P C M s} \Delta T_{M P C M s}}
$$

where $\dot{m}_{M P C M s}$ and $\triangle T_{M P C M s}$ are the mass flow rate of the MPCM slurry and the temperature difference between the inlet and outlet slurry temperatures, respectively.

The overall heat transfer coefficient was also determined as follows:

$$
U_{o}=\frac{\dot{Q}}{A \cdot \mathrm{LMTD}}
$$

where $A$ is total heat transfer surface area, and LMTD is log mean temperature difference which was calculated using the following equation considering a counter flow heat exchanger configuration:

$$
\mathrm{LMTD}=\frac{\left(T_{h, i}-T_{c, o}\right)-\left(T_{h, o}-T_{c, i}\right)}{\ln \left(\frac{T_{h, i}-T_{c, o}}{T_{h, o}-T_{c, i}}\right)}
$$


where $T_{h, i}, T_{h, o}, T_{c, i}$, and $T_{c, o}$ are inlet and outlet fluid temperatures on the hot side, inlet and outlet fluid temperatures on the cold side, respectively.

The total energy efficiency of the ground source heat pump system is represented by the coefficient of performance $\left(\mathrm{COP}_{\mathrm{sys}}\right)$, which is defined as follows:

$$
\mathrm{COP}_{\text {sys }}=\frac{\dot{Q}_{e}}{\dot{W}_{\text {in,total }}}
$$

where $\dot{W}_{i n, t o t a l}$ is total input power and $\dot{Q}_{e}$ is the heat transferred in the evaporator, which are calculated using the following Equations (6) and (7), respectively.

$$
\dot{W}_{\text {in,total }}=\dot{W}_{h p}+\dot{W}_{p}
$$

where $\dot{W}_{h p}$ and $\dot{W}_{p}$ are the electrical power consumed by the heat pump unit and the pump, respectively.

$$
\dot{Q}_{e}=\dot{Q}_{g}-\dot{W}_{h p}-\dot{W}_{p}
$$

where $\dot{Q}_{g}$ is the amount of heat transferred to the ground.

Thus, equation (5) can be rewritten as follows:

$$
\mathrm{COP}_{\mathrm{sys}}=\frac{\dot{Q}_{g}-\dot{W}_{h p}-\dot{W}_{p}}{\dot{W}_{h p}+\dot{W}_{p}}
$$

Another performance metric used to determine the effectiveness of heat transfer fluids is the heat load-to-pumping power ratio, which is defined by the following equation.

$$
\eta=\frac{\dot{Q}_{g}}{\dot{W}_{p}}
$$

$\eta$ has been used to evaluate heat transfer fluids in terms of their ability to transport thermal energy within the system. A performance efficiency coefficient (PEC) 
was also used to compare heat transfer fluids from the energy point of view, which is defined as the ratio of the heat load-to-pumping power ratios between MPCM slurry and water, as follows:

$$
\mathrm{PEC}=\frac{\eta_{M P C M s}}{\eta_{\text {Water }}}
$$

Uncertainty propagation analysis was carried out using the multivariate error formula described in NIST Technical Note 1297 [28]. The experimental uncertainties associated with overall heat transfer coefficient, performance efficiency coefficient, heat load-to-pumping power ratio, and coefficient of performance were $5.5 \%, 3.2 \%, 2.3 \%$, and $2.8 \%$, respectively.

\section{Results and Discussions}

\subsection{Characterization of MPCM Slurries}

MPCM samples manufactured by Thies Technology Inc. were used as heat transfer fluids in the field experiments. The MPCM particles in all the samples consisted of methyl stearate as a phase change material (PCM) and polyurea as a shell material. All MPCM samples were fabricated by the same proprietary encapsulation procedure based on the interfacial polymerization encapsulation protocol, which is widely used to produce microcapsules loaded with water-immiscible liquids. Representative MPCM particle size distribution was obtained by using optical microscopy with Zeiss microscope (x400) as used by previous studies $[12,19,20,23]$. As shown in Fig. 4, an optical photomicrograph of the CT03 sample shows that all MPCM particles had a spherical shape. The particle size ranged from 0.5 to $10 \mu \mathrm{m}$ and average particle diameter was $4.2 \mu \mathrm{m}$. Most of MPCM 
particles had a diameter ranged from 0.5 to $5 \mu \mathrm{m}$ and less than $10 \%$ of MPCM particles had a diameter greater than $5 \mu \mathrm{m}$.

Fig. 4. Optical micrograph of MPCM slurry (sample CT03), magnification: 400X

Differential scanning calorimetry (DSC) tests were carried out to determine the melting and crystallization points and the latent heat of fusion (LHF) of MPCM. The DSC tests were run using a TA Instrument 291 DSC unit at a constant heating and cooling rate of $5{ }^{\circ} \mathrm{C} / \mathrm{min}$. Figure 5 shows DSC results for a single MPCM sample (CT01). The melting temperature, $38.4{ }^{\circ} \mathrm{C}$, was determined by following standard ASTM DSC procedures as used by a previous study [29]. The crystallization point, $38.3{ }^{\circ} \mathrm{C}$, was determined by the same approach described above and using the corresponding exothermic DSC curve. In addition, the LHF of MPCM was determined by calculating the amount of area enclosed by the baseline and endothermic curve (or exothermic curve) [30]. Thermophysical properties of MPCM in all MPCM samples are shown in Table 2. As Table 2 shows, the LHF of MPCM is in the range of 130 to $190 \mathrm{~J} / \mathrm{g}$ and the subcooling of MPCM is up to a maximum of $5{ }^{\circ} \mathrm{C}$ for MPCM batch CT03. Also, MPCM particle diameter in all the samples is less than $10 \mu \mathrm{m}$. Percentage of shell material (i.e. encapsulant) was determined using DSC data and Equation (11) as follows.

$$
\% \text { Shell Material }=\left(1-\frac{\lambda_{M P C M}}{\lambda_{P C M}}\right) \cdot 100
$$


As shown in Table 2, the percentage of shell material varies between 20 and $44 \%$ on a mass basis, which directly correlates with the amount of LHF in each MCPM sample.

Fig. 5. DSC curve of MPCM (sample CT01)

Table 2. Thermophysical properties of MPCM samples

The mass fraction of MPCM slurries is usually kept below $15 \%$ to avoid clogging in pipes and non-Newtonian flow behavior. In addition, higher mass fractions lead to higher viscosity and suppressed or attenuated momentum transfer as reported by previous studies $[19,20,23,26]$. The mass fractions reported in Table 3 were obtained after filling the field heat transfer system with MPCM slurries. Thermophysical properties of MPCM slurries used in the laboratory and field tests were determined by taking several samples from the heat transfer loop. The volume and mass of each sample were measured to determine the density of MPCM slurry. The viscosity of MPCM slurry was measured using a coaxial rotating drum viscometer, which was calibrated with a reference fluid. Thermal conductivity was calculated using the Maxwell correlation as in a previous study [26]. Table 3 shows the thermophysical properties of water and MPCM slurries at $40{ }^{\circ} \mathrm{C}$, which was the average fluid temperature during the experiments. Effective amount of latent heat is shown in Table 3, which is defined as MPCM mass fraction times the latent heat of PCM. 
When MPCM slurries as HTF flow through the system under continuous pumping condition, aggregation of MPCM particles should be prevented. In general, suitable dispersing agents or surfactants should be used to avoid flocculation or aggregation of particles; however, small amounts should be used to avoid greater viscosity. In the current study, a tiny amount of surfactant was used to avoid particle aggregation.

Table 3. Thermophysical properties of MPCM slurries

\subsection{Thermal Performance of MPCM Slurry in Laboratory Tests}

MPCM slurry sample (CT00) was used and tested under laboratory conditions to see how MPCM slurry may enhance the overall performance of a coil heat exchanger (CHX) before deploying MPCM slurries (CT01, CT02, and CT03) in the field GSHP systems. Figure 6(a) shows the heat transfer rates for water and MPCM slurry at a mass fraction of $8.7 \%$ at different flow rate conditions. Experimental results show that higher flow rates result in higher heat transfer rates due to the increased momentum transfer during the heat transfer process. In addition, the mass fraction of MPCM in the slurries also led to greater heat transfer rate with a corresponding enhancement of about $29 \%$ when compared with water. This can be attributed to the high heat capacity of MPCM due to the LHF of PCM, which enhances heat transfer performance of MPCM slurry [19, 20, 32]. As shown in Fig. 6(b), the overall heat transfer coefficient values for the MPCM slurries were greater than those for water at a constant flow rate condition and the enhancement was up to $41 \%$ when compared to water's values. Similar observations 
have been made when using MPCM slurry using an internally-corrugated coil heat exchanger [13], which suggests that MPCM slurry should be used in combination with coil heat exchanger to achieve better system performance.

Fig. 6. (a) Heat transfer rates and (b) overall heat transfer coefficient as a function of flow rate

Figure 7 shows pressure drop for water and 8.7 \% MPCM slurry as a function of flow rate. Pressure drop was measured between the inlet and outlet of the inner tube of the CHX. Experimental results show that pressure drop of MPCM slurry was greater than that for water by up to about $22 \%$ because of the higher viscosity [23, 24].

In order to determine the benefits of using MPCM slurry as a HTF, energy evaluation analysis was performed by taking into account heat transfer and pressure drop data [33-36]. In the study, the performance efficiency coefficient (PEC) was defined and calculated using Equation (10). Figure 8 shows that the PEC values for the $8.7 \%$ MPCM slurry were about $7 \%$ higher than for water. This can suggest that using MPCM slurry can improve the overall performance of a CHX by considerably increasing the amount of heat transfer, even though MPCM slurries have higher viscosity, which leads to higher pressure drop and pumping power.

Fig. 7. Pressure drop for water and $8.7 \%$ MPCM slurry as a function of flow rate 
Fig. 8. Performance efficiency coefficient as a function of flow rate

\subsection{Thermal Performance of MPCM Slurries in Field Tests}

Field tests were conducted under normal operating conditions to meet the customer's performance expectations. Experiments in the field were performed to determine how MPCM slurries affect the thermal performance of a GSHP system when compared to water, which was the existing HTF used in the field. Firstly, the experiments with water were performed to obtain reference data for comparison purposes. In addition, the operating temperature range obtained from the water tests was used to identify PCM with suitable melting and solidification points to fully take advantage of the PCM's LHF. Then, three different MPCM batches (CT01, CT02, and CT03) as shown in Table 2 were field-tested. The working flow rate for each MPCM slurry was determined based on the heat transfer rate of water for comparison purposes. A centrifugal pump similar to the exiting GSHP pump was used for the first two field tests. In the third field test, a progressive cavity pump was used because it was considered to be suitable for ensuring MPCM slurry durability for thousands of pump-cycles $[19,20]$.

Figure 9 shows the variations in the coefficient of performance for the GSHP system $\left(\mathrm{COP}_{\text {sys }}\right)$ and the heat transfer rate in the first demonstration field test as a function of time of the day. Experimental results show that heat transfer rates varied from 7.5 to $10 \mathrm{~kW}$, which were governed by the variable cooling demand in the building. The $\mathrm{COP}_{\text {sys }}$ was in the range of 2.5 to 4.0 and the variation in the $\mathrm{COP}_{\text {sys }}$ was consistent with that of the heat transfer rate [37]. It was found that the heat transfer rate had a direct effect on $\mathrm{COP}_{\text {sys. }}$. 
Fig. 9. Heat transfer rate and coefficient of performance as a function of time of day in the demonstration 1: MPCM sample-CT01

Figure 10 shows the heat load-to-pumping power ratio $(\eta)$ for each field test as a function of heat transfer rate at different flow rate $(\dot{V})$ conditions for MPCM slurry and water as shown in Table 4. The difference between the flow rate of MPCM slurry and water is due to the increased heat capacity of MPCM slurry for identical heat rate values. Experimental results show that $\eta$ increased with the heat transfer rate and the $\eta$ values of MPCM slurries were higher than those for water. This is because using MPCM slurry resulted in reduced pumping power consumption due to the greater heat carrying capacity of MPCM slurry as shown in Table 4. The improvements in the $\eta$ of MPCM slurries were around $34 \%, 15 \%$, and $10 \%$ for the $1^{\text {st }}, 2^{\text {nd }}$, and $3^{\text {rd }}$ demonstrations, respectively, when compared to water, as shown in Table 5. The $\eta$ enhancements correlate well with the amount of effective LHF present within the MPCM slurry as shown in Table 3. Therefore, higher heat carrying capacity of MPCM slurry led to a reduction of the required flow rate of HTF in the GSHP system and consequently saved pumping power. It was also found that the overall heat transfer coefficient values of MPCM slurries were almost the same as those of water even at lower flow rates, which indicates that the $\mathrm{CHX}$ was capable of promoting adequate internal convection even MPCM slurries with higher viscosity values flowed through it. 
Fig. 10. Heat load-to-pumping ratios as a function of heat transfer rate at (a) demonstration 1; (b) demonstration 2; (c) demonstration 3

Table 4. Heat load-to-pumping power ratio, flow rate, pumping power consumption, and overall heat transfer coefficient in the demonstrations

Table 5. Ratio of heat load-to-pumping power ratio, flow rate ratio, pumping power ratio, and overall heat transfer coefficient ratio between MPCM slurry and water

The coefficient of performance for the GSHP systems $\left(\mathrm{COP}_{\text {sys }}\right)$ with water and MPCM slurry as heat transfer fluids are shown in Fig. 11. Experimental results show that the $\mathrm{COP}_{\text {sys }}$ ranged from 3.0 to 4.0 and the $\mathrm{COP}_{\text {sys }}$ value for the high heat load case (Demonstration 3) was greater than that of the lower heat load cases [37]. The values of the $\mathrm{COP}_{\text {sys }}$ with the MPCM slurry were higher than those of water at constant heat load and the enhancement of the $\mathrm{COP}_{\text {sys }}$ was in the range of 4.2 to $4.9 \%$. It was found that the GSHP system with MPCM slurry could transport the same amount of heat but at lower flowrate when compared to water, due to the LHF of PCM in the slurry. This suggests that MPCM slurries can become viable heat transfer fluids in heating and cooling applications in terms of the overall performance.

Fig. 11. Coefficient of performance of ground source heat pump system 


\subsection{Durability of MPCM Slurries in Field Tests}

Durability of MPCM particles is one of the most important parameters for the use of MPCM slurry in heating and cooling applications. MPCM slurries as HTF need to be able to withstand continuous pumping conditions during long-term operations. The effective specific heat of MPCM slurry using Equation (2) was used to determine the effect of pump cycles on thermal performance, as suggested in previous studies [13, 23]. The durability was determined based on whether or not the value of the effective specific heat remains constant during thousands of cycles. Furthermore, MPCM samples were collected and inspected frequently using a microscope to detect visually any sign of degradation. Figure 12 shows the enhancement in specific heat of MPCM slurry as a function of number of flow cycles or pump-cycles. MPCM slurries in the first and second demonstrations were circulated using a centrifugal pump, and the MPCM particles were able to withstand continuous pumping conditions for 14,402 cycles and 38,805 cycles, respectively. However, clumps of MPCM particles were observed in some of the samples taken from the test loop due to the breakage of MPCM particles and consequently the GSHP system had to be turned off. This was a necessary step to keep broken MPCM particles from piling up in the gap between the impeller and housing of the centrifugal pump, and other components such as valves and pipes. Experimental results also show that the CT02 MPCM batch (6 \% by weight) was more durable than the CT01 MPCM batch (11\% by weight). Therefore, it may be concluded that lower concentration or greater interparticle distance within the slurry is more favorable in terms of durability. From the first and second demonstrations, it was concluded that the centrifugal pump was not suitable for the MPCM particles in terms of the durability. Furthermore, MPCM 
capsules were found not to be strong enough to be pumped by the centrifugal pump. Since previous studies $[19,20]$ reported that a progressive cavity pump is suitable for MPCM slurry flow, a Moyno progressive cavity pump was used in the third demonstration. As a result of the third demonstration, MPCM particles were able to withstand continuous pumping conditions after circulating 123,252 cycles without significant degradation of effective specific heat of MPCM slurry. However, the possible breakage and agglomeration of the MPCM were detected at the end of the demonstration and this in turn increased the pressure drop of the system.

Fig. 12. Enhancement in the specific heat of MPCM slurries as a function of number of flow cycle

Based on the durability results, life span of MPCM slurry was estimated when applied into the whole GSHP system loop. It was assumed that MPCM slurry flowed at the same flow rate as the existing HTF (i.e. water). The estimated life span of MPCM slurry $\left(L S_{M P C M S}\right)$ was calculated by using the following equation.

$$
L S_{M P C M s}[\text { year }]=T_{\text {cycle }}\left[\frac{\min }{\text { cycle }}\right] \times N_{\text {cycle }}[\text { cycle }] \times \frac{1 h}{60 \min } \times \frac{1 \text { day }}{24 h} \times \frac{\text { year }}{365 \text { day }}
$$

where $N_{\text {cycle }}$ is the number of flow cycles. $T_{\text {cycle }}$ is time taken by HTF to circulate through the whole GSHP loop, which was calculated by dividing the total volume of heat transfer fluid within the GSHP loop $\left(V_{t, G S H P}\right)$ by the working flow rate of the fluid $\left(\dot{V}_{G S H P}\right)$. 
As shown in Table 6, the maximum estimated service life of MPCM slurry is about 10.5 years for the third demonstration, when a progressive cavity pump was used. The estimated service life of MPCM slurries circulated by a centrifugal pump is up to 3.3 years. This certainly suggests that a progressive cavity pump is more suitable than the dynamic pump for MPCM slurry applications. However, since lots of centrifugal pumps are widely used in industry and other sectors, the durability of MPCM slurries still has to be enhanced for their widespread implementation across multiple applications as HTF.

Table 6. Estimated life span of MPCM slurry

\section{Conclusions}

MPCM slurries were field-tested in the GSHP system located in Texas, United States to validate the heat transfer performance and durability as HTF. In terms of heat transfer performance, experimental results showed that the heat load-to-pumping power ratio of MPCM slurry was from 56.1 to 96.1 with an enhancement of $34 \%$ when compared to water. In addition, the $\mathrm{COP}_{\text {sys }}$ of the GSHP system with MPCM slurries was in the range of 3.2 to 4.0 and the enhancement was up to $4.9 \%$. It can be concluded that MPCM slurry can become a viable heat transfer fluid in a host of heating and cooling applications. This may be attributed to the LHF of the PCM when PCM undergoes phase change (i.e. solid-liquid transformation), which leads to enhanced heat carrying capacity and a reduction in the required flow rate. Consequently, energy saving can be materialized through decreased pumping power. In terms of durability, no considerable 
damage of the MPCM particles was detected after 123,252 circulation cycles when using a progressive cavity pump. The estimated life span of MPCM slurry was increased from 3.3 to 10.5 years when using a progressive cavity pump instead of a centrifugal pump. Even though it was found that the progressive cavity pump is more suitable for MPCM slurry applications, future studies should be undertaken for evaluating the durability of MPCM capsules for applications when different pumps may be used. The effects of number of cycles on MPCM durability will be determined by inspecting representative MPCM particles, and measuring MPCM thermal properties as a function of the number of cycles. In addition, future studies should consider better thermal properties of PCM including greater latent heat of fusion of PCM.

\section{ACKNOWLEDGEMENTS}

The authors would like to acknowledge the support from the Department of Defense Environmental Security Technology Certification Program for ESTCP Project EW-201154, and the U.S. Army Corps of Engineers, Engineer and Development Research Center. The authors are also thankful to Dr. Gary E. Phetteplace of GWA Research LLC, and Brent Cabaniss of the Directorate of Public Works, Fort Hood, Texas for their invaluable support during the execution of the field study.

\section{NOMENCLATURE}

$A \quad$ Heat transfer surface area $\left(\mathrm{m}^{2}\right)$

$c_{p} \quad$ Specific heat $\left(\mathrm{kJ} / \mathrm{kg}-{ }^{\circ} \mathrm{C}\right)$

$c_{p, e f f} \quad$ Effective specific heat $\left(\mathrm{kJ} / \mathrm{kg}-{ }^{\circ} \mathrm{C}\right)$

COP Coefficient of performance

LMTD Log mean temperature difference 


$\begin{array}{ll}L S_{M P C M s} & \text { Estimated life span of MPCM slurry (years) } \\ \dot{m} & \text { Mass flow rate }(\mathrm{kg} / \mathrm{s}) \\ N_{c y c l e} & \text { Number of flow cycles (cycles) } \\ \text { PEC } & \text { Performance efficiency coefficient } \\ \dot{Q} & \text { Heat transfer rate }(\mathrm{kW}) \\ T & \text { Fluid temperature }\left({ }^{\circ} \mathrm{C}\right) \\ T_{c, i} & \text { Inlet fluid temperature on a cold side }\left({ }^{\circ} \mathrm{C}\right) \\ T_{c, o} & \text { Outlet fluid temperature on a cold side }\left({ }^{\circ} \mathrm{C}\right) \\ T_{c y c l e} & \text { Time taken by heat transfer fluid to circulate through the whole ground } \\ T_{h, i} & \text { source heat pump loop (min/cycles) } \\ T_{h, o} & \text { Inlet fluid temperature on a hot side }\left({ }^{\circ} \mathrm{C}\right) \\ \Delta T & \text { Outlet fluid temperature on a hot side }\left({ }^{\circ} \mathrm{C}\right) \\ U_{o} & \text { Difference between inlet and outlet fluid temperatures }\left({ }^{\circ} \mathrm{C}\right) \\ \dot{V} & \text { Overall heat transfer coefficient }\left(\mathrm{kW} / \mathrm{m} 2-{ }^{\circ} \mathrm{C}\right) \\ V_{t, G S H P} & \text { Volumetric flow rate }(1 / \text { min) } \\ \dot{W} & \text { Total volume of heat transfer fluid in ground source heat pump loop (liters) }\end{array}$

\section{Greek Symbols}

$\eta \quad$ Heat load to pumping power ratio

$\lambda \quad$ Latent heat of fusion, $\mathrm{J} / \mathrm{g}$

\section{Subscripts}

$\begin{array}{ll}c & \text { crystallization } \\ e & \text { evaporator } \\ g & \text { ground } \\ h p & \text { heat pump } \\ \text { in } & \text { inlet } \\ \text { in, total } & \text { total input } \\ m & \text { melting } \\ M P C M & \text { microencapsulated phase change material } \\ M P C M s & \text { microencapsulated phase change material slurry } \\ \text { out } & \text { outlet } \\ p & \text { pump } \\ P C M & \text { phase change material }\end{array}$




\section{REFERENCES}

[1] O. Ozyurt, D.A. Ekinci, Experimental study of vertical ground-source heat pump performance evaluation for cold climate in Turkey, Applied Energy 88 (2011) 12571265.

[2] A. Hepbasli, O. Akdemir, E. Hancioglu, Experimental study of a closed loop vertical ground source heat pump system, Energy Conversion and Management 44 (2003) 527-548.

[3] A. Michopoulos, D. Bozis, P. Kikidis, K. Papakostas, N.A. Kyriakis, Three-years operation experience of a ground source heat pump system in Northern Greece, Energy and Buildings 39 (2007) 328-334.

[4] A.M. Omer, Ground-source heat pumps systems and applications, Renewable and Sustainable Energy Reviews 12 (2008) 344-371.

[5] K. Bakirci, Evaluation of the performance of a ground-source heat-pump system with series GHE (ground heat exchanger) in the cold climate region, Energy 35 (2010) 3088-3096.

[6] C.J. Wood, H. Liu, S.B. Riffat, An investigation of the heat pump performance and ground temperature of a piled foundation heat exchanger system for a residential building, Energy 35 (2010) 4932-4940.

[7] E. Pulat, S. Coskun, K. Unlu, N. Yamankaradeniz, Experimental study of horizontal ground source heat pump performance for mild climate in Turkey, Energy 34 (2009) 1284-1295.

[8] H. Esen, M. Inalli, M. Esen, K. Pihtili, Energy and exergy analysis of a groundcoupled heat pump system with two horizontal ground heat exchangers, Building and Environment 42 (2007) 3606-3615.

[9] K. Nagano, T. Katsura, S. Takeda, Development of a design and performance prediction tool for the ground source heat pump system, Applied Thermal Engineering 26 (2006) 1578-1592.

[10] A. Hepbasli, O. Akdemir, Energy and exergy analysis of a ground source (geothermal) heat pump system, Energy Conversion and Management 45 (2004) 737753.

[11] Y. Yamagishi, T. Sugeno, T. Ishige, An evaluation of microencapsulated PCM for use in cold energy transportation medium, Proceedings of the Intersociety Energy Conversion Engineering Conference (1996) 2077-2083.

[12] X. Wang, J. Niu, Y. Li, X. Wang, B. Chen, R. Zeng, Q. Song, Y. Zhang, Flow and heat transfer behaviors of phase change material slurries in a horizontal circular tube, International Journal of Heat and Mass Transfer 50 (2007) 2480-2491.

[13] M. Kong, K. Yu, J.L. Alvarado, W. Terrell, Thermal performance of microencapsulated phase change material slurry in a coil heat exchanger, Journal of Heat Transfer 137 (2015) 071801-1-8. 
[14] S.D. Sharma, D. Buddhi, R.L. Sawhney, Accelerated thermal cycle test of latent heat-storage materials, Solar Energy 66 (1999) 483-490.

[15] B.M. Diaconu, S. Varga, A.C. Oliveira, Experimental assessment of heat storage properties and heat transfer characteristics of a phase change material slurry for air conditioning applications, Applied Energy 87 (2010) 620-628.

[16] C. Alkan, A. Sari, A. Karaipekli, O. Uzun, Preparation, characterization, and thermal properties of microencapsulated phase change material for thermal energy storage, Solar Energy \& Solar Cells 93 (2009) 143-147.

[17] J. Giro-Paloma, C. Barreneche, M. Delgado, M. Martinez, A.I. Fernandez, L.F. Cabeza, Physicochemical and thermal study of a MPCM of PMMA shell and paraffin wax as a core, Energy Procedia 48 (2014) 347-354.

[18] J. Giro-Paloma, C. Barreneche, M. Martinez, B. Sumiga, L.F. Cabeza, A.I. Fernandez, Comparison of phase change slurries: physicochemical and thermal properties, Energy 87 (2015) 223-227.

[19] J.L. Alvarado, C. Marsh, C. Sohn, G. Phetteplace, T. Newell, Thermal performance of microencapsulated phase change material slurry in turbulent flow under constant heat flux, International Journal of Heat and Mass Transfer 50 (2007) 1938-1952.

[20] Y. Yamagishi, H. Takeuchi, A.T. Pyatenko, N. Kayukawa, Characteristics of microencapsulated PCM slurry as a heat-transfer fluid, The American Institute of Chemical Engineers Journal 45 (1999) 696-707.

[21] S.K. Roy, S. Sengupta, An evaluation of phase change microencapsules for use in enhanced heat transfer fluids, International Communications in Heat and Mass Transfer 18 (1991) 495-507.

[22] C. Crowe, M. Sommerfeld, Y. Tsuji, Multiphase Flows with Droplets and Particles, CRC Press, Boca Raton, FL, 1998.

[23] H. Taherian, J.L. Alvarado, K. Tumuluri, C. Thies, C. Park, Fluid flow and heat transfer characteristics of microencapsulated phase change material slurry in turbulent flow, Journal of Heat Transfer 136 (2014) 061704-1-7.

[24] M. Kong, J.L. Alvarado, E.M. Languri, An experimental study of heat transfer characteristics of microencapsulated phase change material slurry in a coil heat exchanger, ASME International Mechanical Engineering Congress and Exposition (2013) 63319.

[25] X. Wang, J. Niu, Y. Li, Y. Zhang, X. Wang, B. Chen, R. Zeng, Q. Song, Heat transfer of microencapsulated PCM slurry flow in circular tube, The American Institute of Chemical Engineers Journal 54 (2008) 1110-1120.

[26] M. Kong, J.L. Alvarado, W. Terrell, C. Thies, Performance characteristics of microencapsulated phase change material slurry in a helically coiled tube, International Journal of Heat and Mass Transfer 101 (2016) 901-914. 
[27] J. Giro-Paloma, C. Barreneche, M. Martinez, B. Sumiga, A.I. Fernandez, L.F. Cabeza, Mechanical response evaluation of microcapsules from different slurries, Renewable Energy, 85 (2016) 732-739.

[28] B.N. Taylor, C.E. Kuyatt, Guidelines for evaluating and expressing the uncertainty of NIST measurement results, NIST Technical Note 1297, NIST, Gaithersburg, MD, 1994.

[29] J.L. Alvarado, C. Marsh, C. Sohn, M. Vilceus, V. Hock, G. Phetteplace, T. Newell, Characterization of supercooling suppression of microencapsulated phase change material by using DSC, Journal of Thermal Analysis and Calorimetry, 86 (2006) 505509.

[30] American International Society for Testing and Materials (ASTM) Standard C1784, 14, "Standard Test Method for Using a Heat Flow Meter Apparatus for Measuring Thermal Storage Properties of Phase Change Materials and Products," ASTM International, West Conshohocken, PA, 2014.

[31] J.C. Maxwell, A treatise on Electricity and Magnetism, Dover Publications, Mineola NY, 1954.

[32] M. Kong, Flow and heat transfer characteristics of microencapsulated phase change material slurry in a coil heat exchanger, Doctoral Dissertation, Texas A\&M University, College Station, TX, 2015.

[33] W. Yu, D.M. France, E.V. Timofeeva, D. Singh, J.L. Routbort, Thermophysical property-related comparison criteria for nanofluids heat transfer enhancement in turbulent flow, Applied Physics Letters 96 (2010) 1-3.

[34] H.A. Mohammed, K. Narrein, Thermal and hydraulic characteristics of nanofluid flow in a helically coiled tube heat exchanger, International Communication in Heat and Mass Transfer 39 (2012) 1375-1383.

[35] M.F. Pakdaman, M.A.A. Behabadi, P. Razi, An experimental investigation on thermo-physical properties and overall performance of MWCNT/heat transfer oil nanofluid flow inside vertical helically coiled tubes, Experimental Thermal and Fluid Science 40 (2012) 103-111.

[36] K. Tumuluri, J.L. Alvarado, H. Taherian, C. Marsh, Thermal performance of a novel heat transfer fluid containing multiwalled carbon nanotubes and microencapsulated phase change materials, International Journal of Heat and Mass Transfer 54 (2011) 5554-5567.

[37] W. Yang, Experimental performance analysis of a direct-expansion ground source heat pump in Xiangtan, China, Energy 59 (2013) 334-339. 


\section{Figure Captions List}

Fig. 1. Schematic diagram of experimental setup

Fig. 2. Flow diagram of a heat transfer loop in the field

Fig. 3. Flow diagram of a fully instrumented heat transfer loop

Fig. 4. Optical micrograph of MPCM slurry (sample CT03), magnification: 400X

Fig. 5. DSC curve of MPCM (sample CT01)

Fig. 6. (a) Heat transfer rates and (b) overall heat transfer coefficient as a function of flow rate

Fig. 7. Pressure drop for water and $8.7 \%$ MPCM slurry as a function of flow rate

Fig. 8. Performance efficiency coefficient as a function of flow rate

Fig. 9. Heat transfer rate and coefficient of performance as a function of time of day in the demonstration 1: MPCM sample-CT01

Fig. 10. Heat load-to-pumping ratios as a function of heat transfer rate at (a) demonstration 1; (b) demonstration 2; (c) demonstration 3

Fig. 11. Coefficient of performance of ground source heat pump system

Fig. 12. Enhancement in the specific heat of MPCM slurries as a function of number of flow cycle

\section{Table Captions List}

Table 1. Specifications of the components

Table 2. Thermophysical properties of MPCM samples

Table 3. Thermophysical properties of MPCM slurries

Table 4. Heat load-to-pumping power ratio, flow rate, pumping power consumption, and overall heat transfer coefficient in the demonstrations

Table 5. Ratio of heat load-to-pumping power ratio, flow rate ratio, pumping power ratio, and overall heat transfer coefficient ratio between MPCM slurry and water

Table 6. Estimated life span of MPCM slurry 


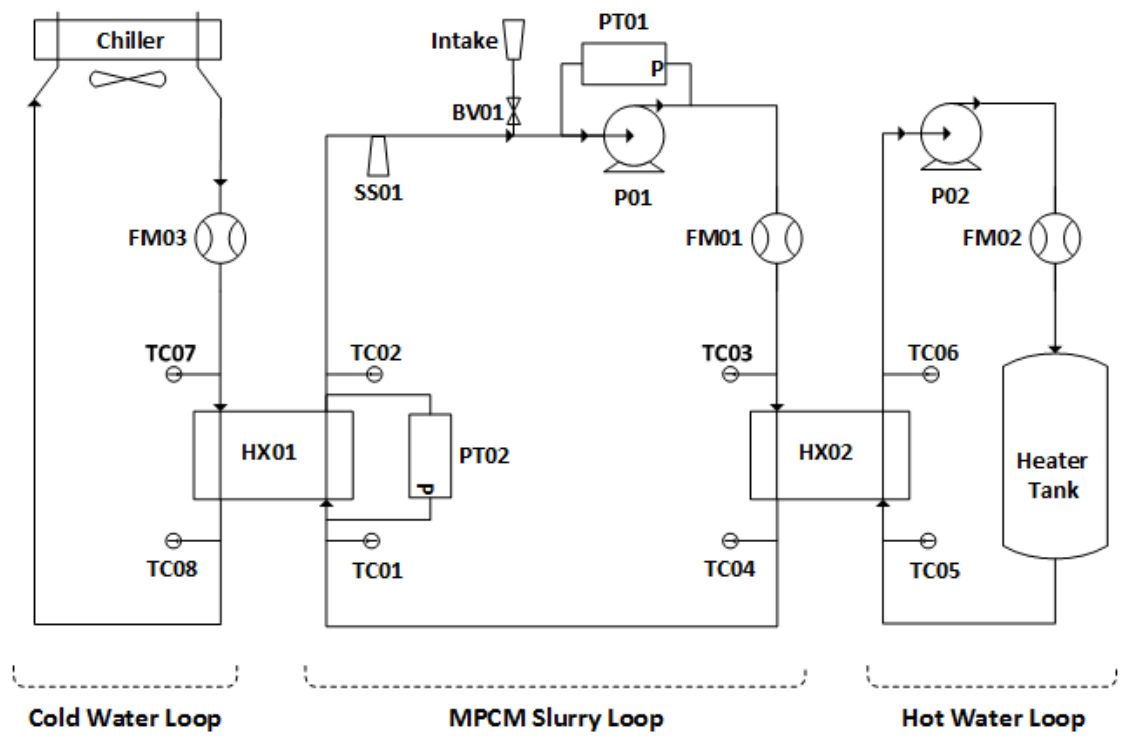

Fig. 1. Schematic diagram of experimental setup 


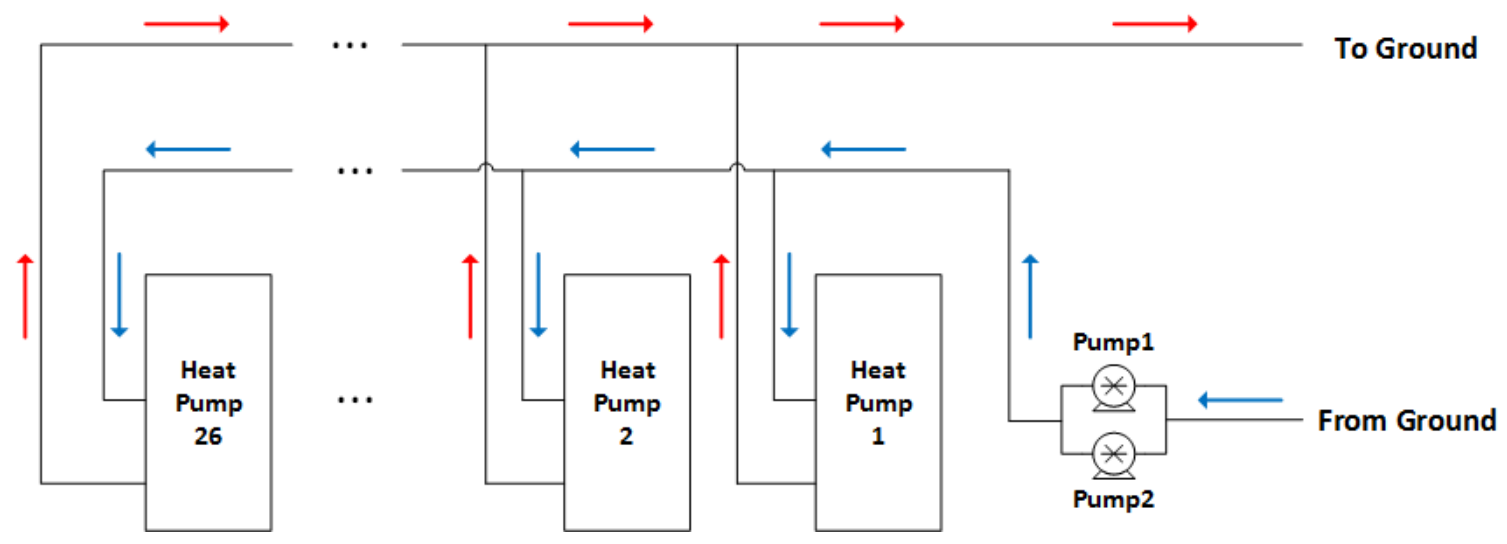

Fig. 2. Flow diagram of a heat transfer loop in the field 


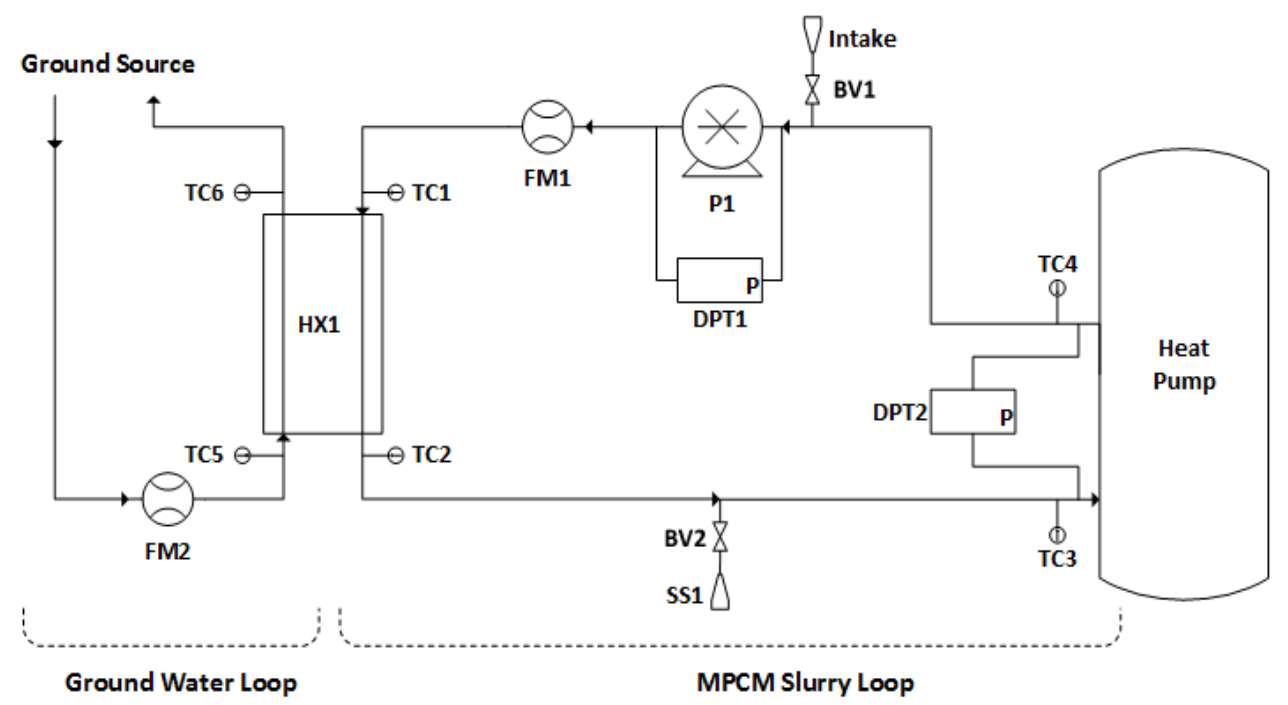

Fig. 3. Flow diagram of a fully instrumented heat transfer loop 


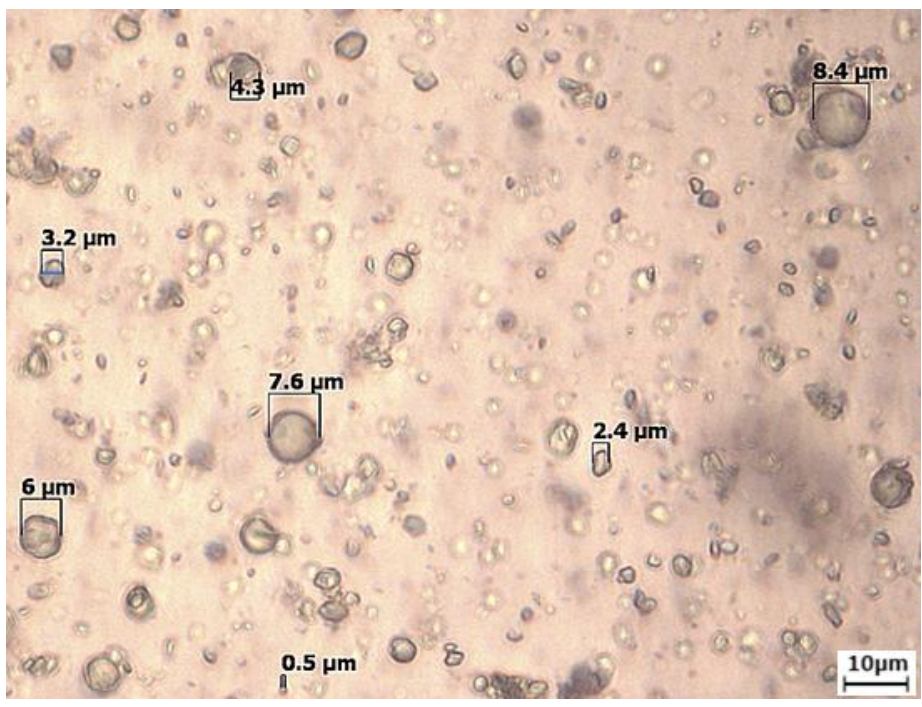

Fig. 4. Optical micrograph of MPCM slurry (sample CT03), magnification: 400X 


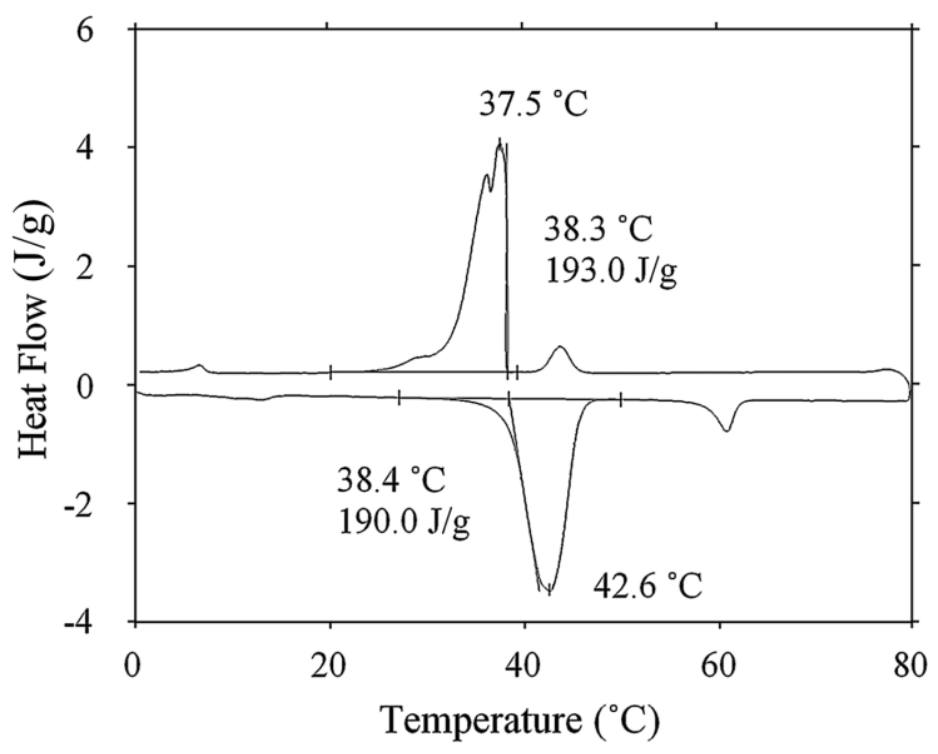

Fig. 5. DSC curve of MPCM (sample CT01) 

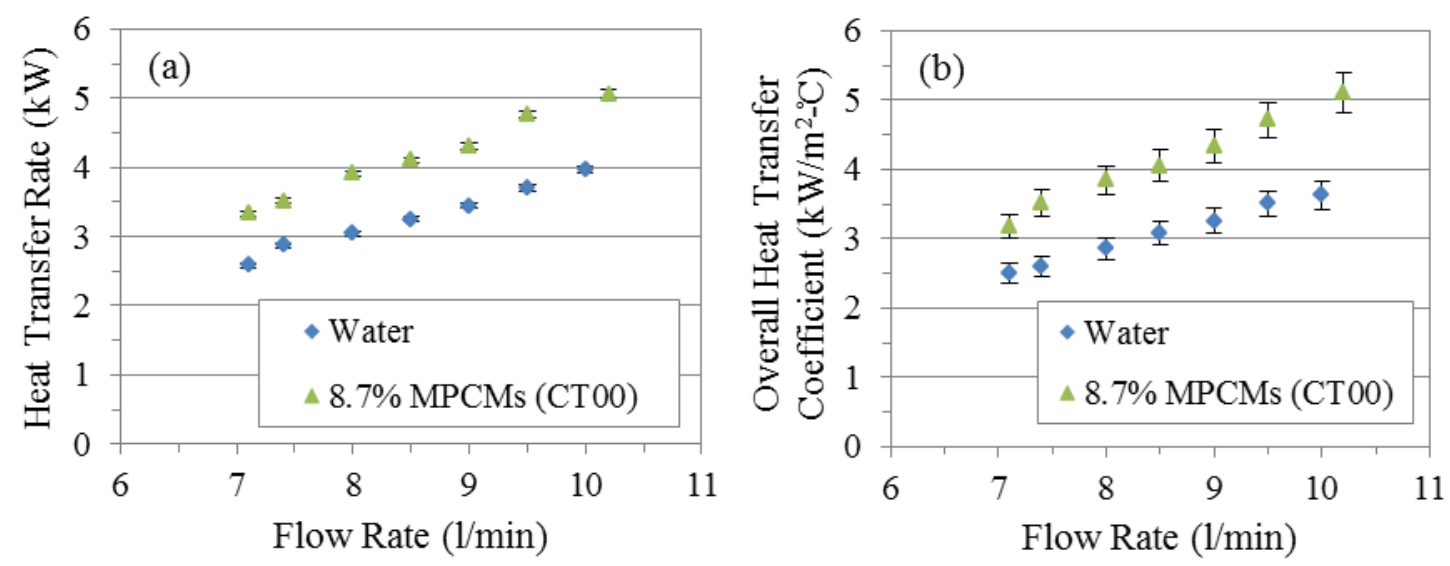

Fig. 6. (a) Heat transfer rates and (b) overall heat transfer coefficient as a function of flow rate 


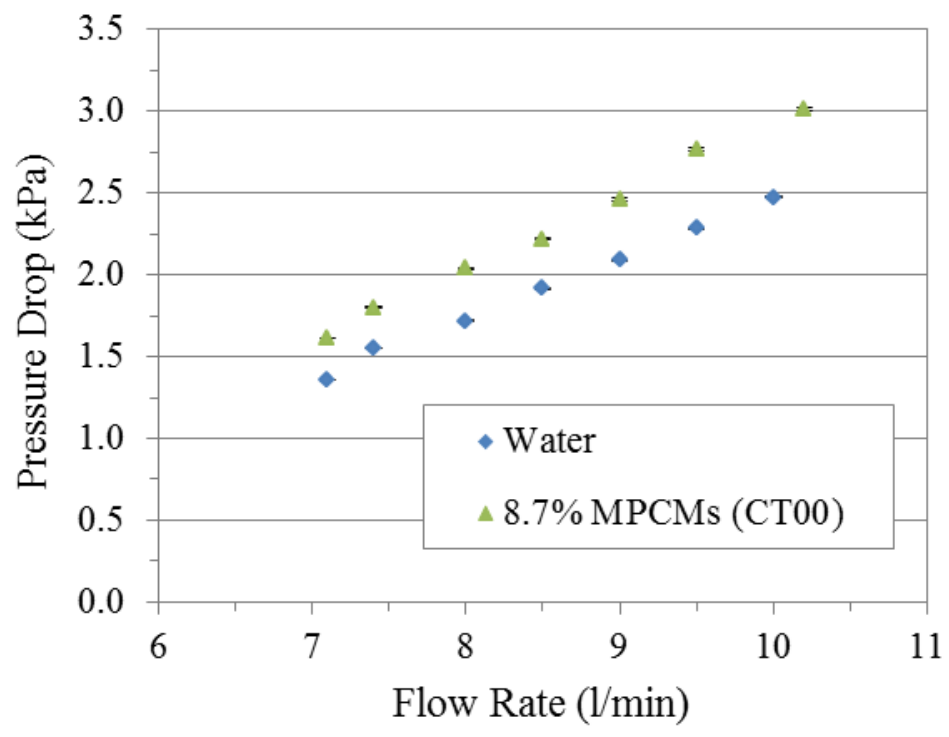

Fig. 7. Pressure drop for water and 8.7 \% MPCM slurry as a function of flow rate 


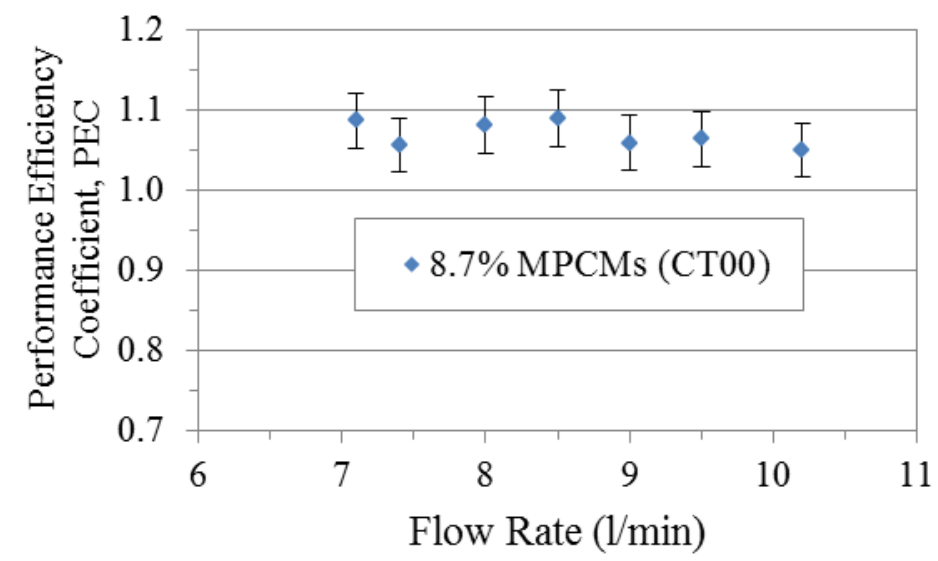

Fig. 8. Performance efficiency coefficient as a function of flow rate 


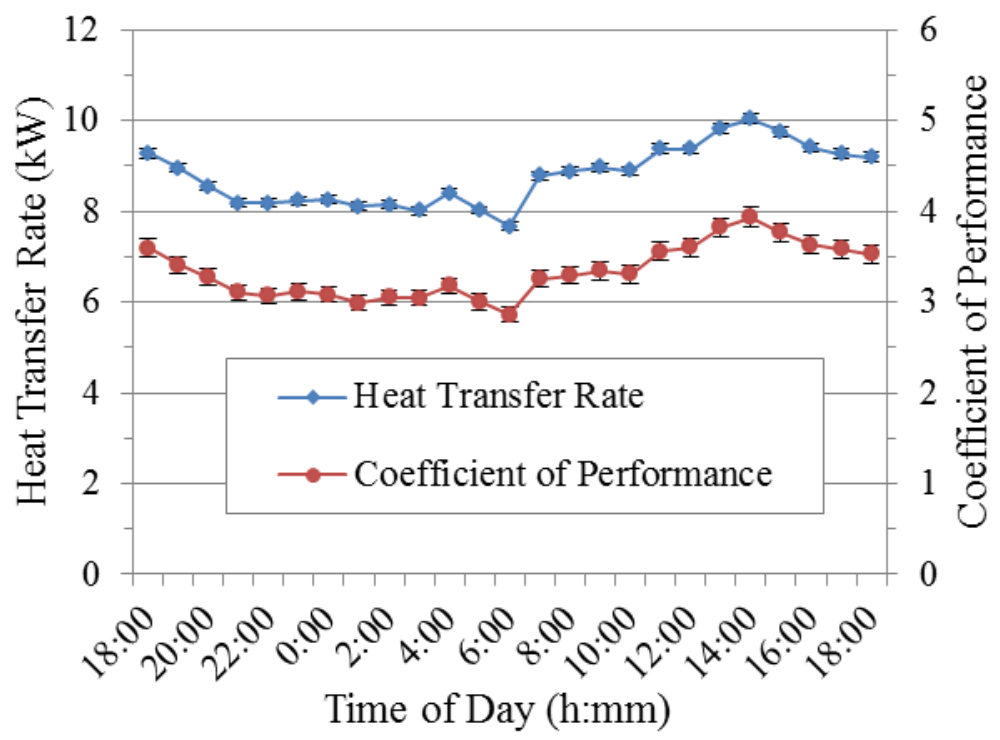

Fig. 9. Heat transfer rate and coefficient of performance as a function of time of day in the demonstration 1: MPCM sample-CT01 

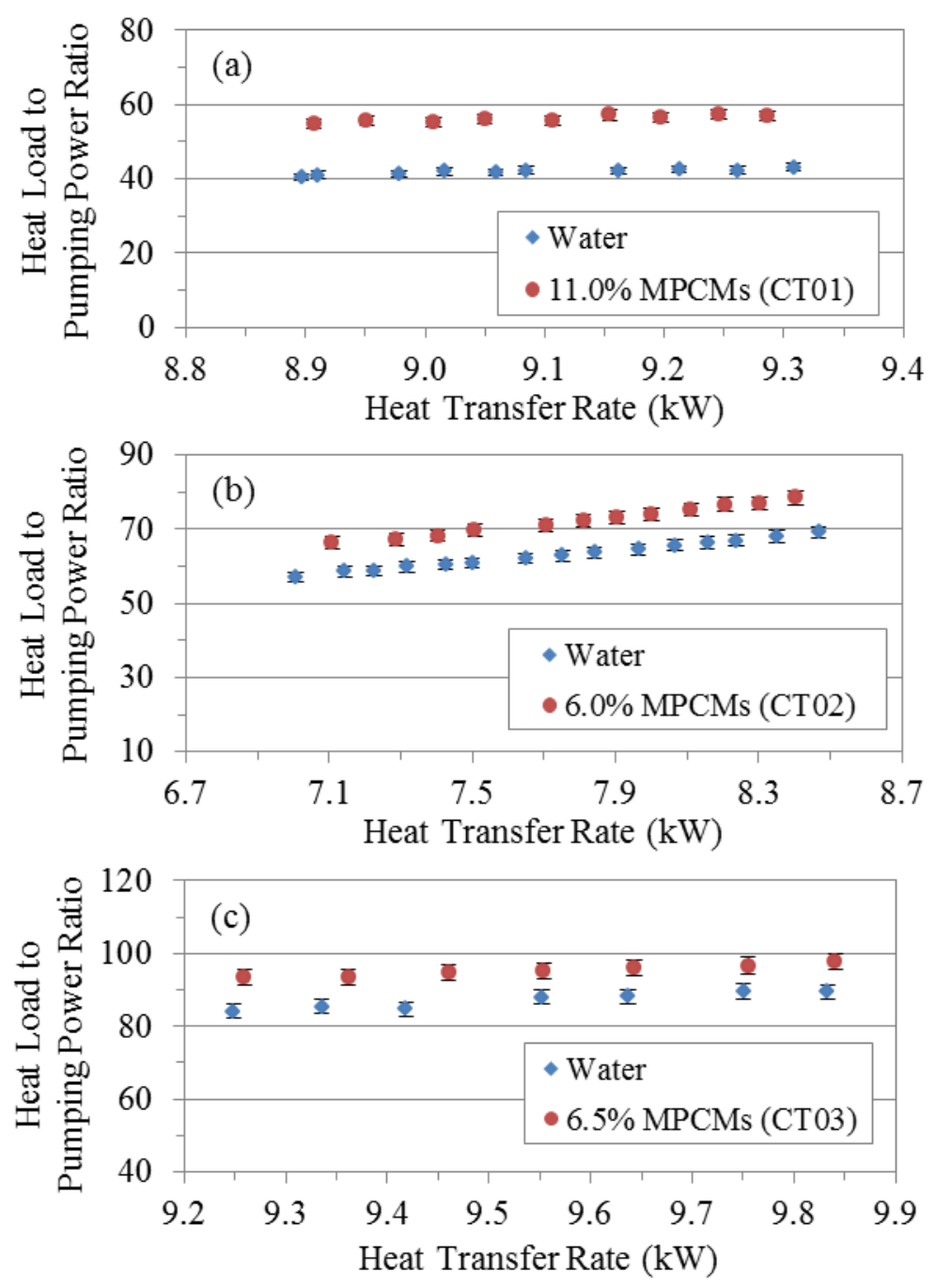

Fig. 10. Heat load-to-pumping ratios as a function of heat transfer rate at (a) demonstration 1; (b) demonstration 2; (c) demonstration 3 


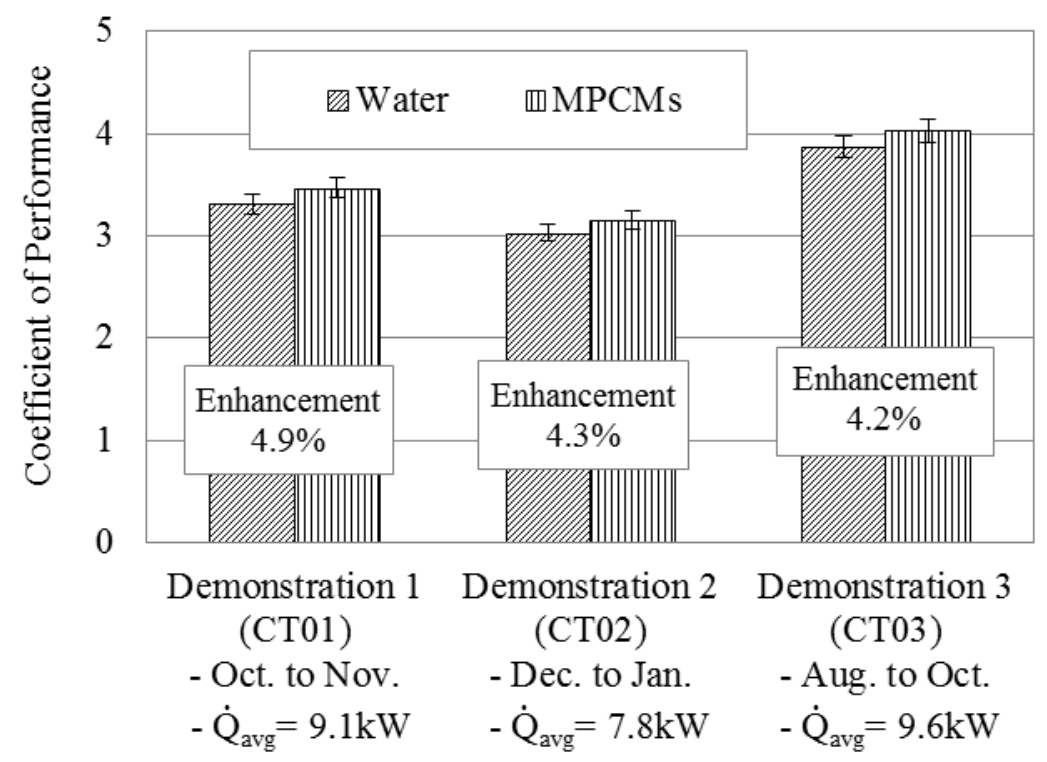

Fig. 11. Coefficient of performance of ground source heat pump system 


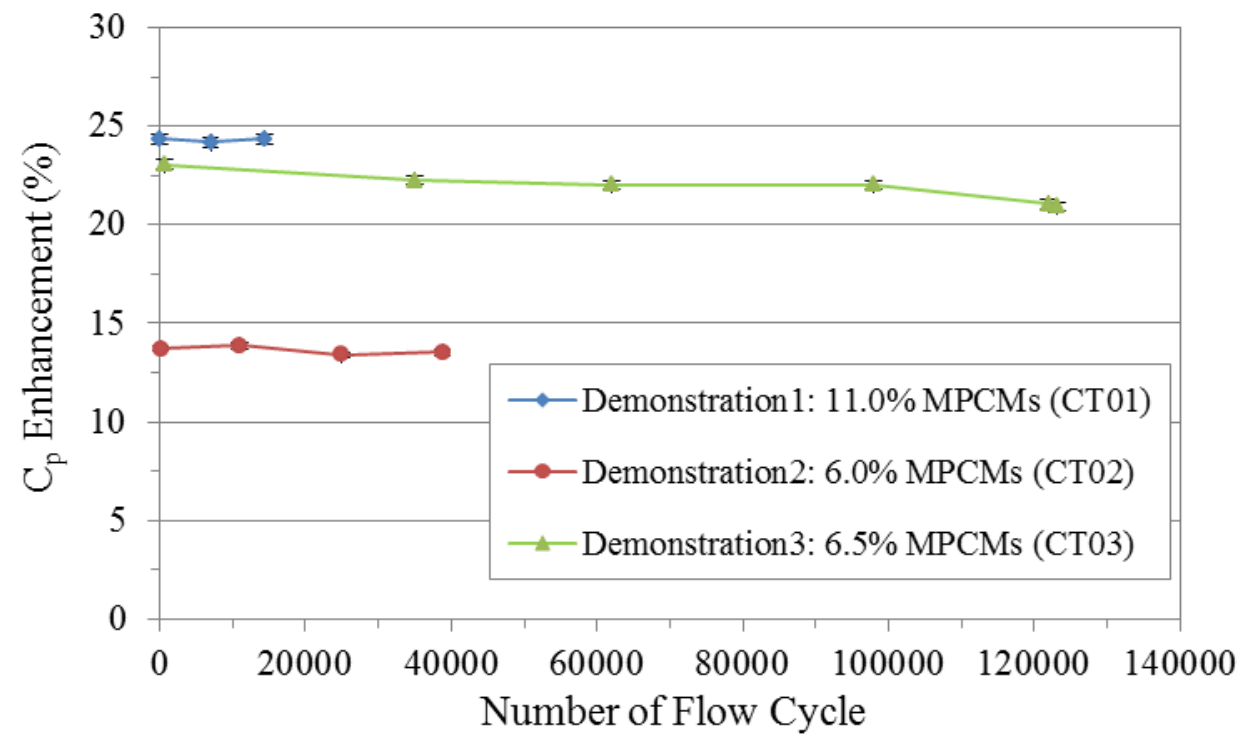

Fig. 12. Enhancement in the specific heat of MPCM slurries as a function of number of flow cycle 
Table 1. Specifications of the components

\begin{tabular}{|l|l|}
\hline Components & Technical Specifications \\
\hline Centrifugal Pump & $\begin{array}{l}\text { - Manufacturer: Armstrong Pump } \\
\text { - Max. flow rate: } 189.31 / \mathrm{min}, \text { Max. discharging pressure: } 68.9 \mathrm{kPa}\end{array}$ \\
\hline Progressive Cavity Pump & $\begin{array}{l}\text { - Manufacturer: Moyno Pump } \\
\text { - Max. flow rate: } 18.9 \text { 1/min, Max. discharging pressure: } 689.5 \mathrm{kPa}\end{array}$ \\
\hline Coil Heat Exchanger & $\begin{array}{l}\text { - Manufacturer: Packless Industries } \\
\text { - Capacity: 4 tons }(14.1 \mathrm{~kW})\end{array}$ \\
\hline Magnetic Flow Meter & $\begin{array}{l}\text { - Manufacturer: Omega } \\
\text { - Measuring range: } 0-75.71 / \mathrm{min}, \text { Accuracy: } \pm 1 \%\end{array}$ \\
\hline $\begin{array}{l}\text { Differential Pressure } \\
\text { Transducer }\end{array}$ & $\begin{array}{l}\text { - Manufacturer: Cole-Parmer } \\
\text { - Measuring range: } 0-34.5 \mathrm{kPa}, \text { Accuracy: } \pm 0.25 \%\end{array}$ \\
\hline Thermocouple & $\begin{array}{l}\text { - Manufacturer: Omega } \\
\text { - Accuracy: } \pm 0.4 \%\end{array}$ \\
\hline Voltage Differential Probe & $\begin{array}{l}\text { - Manufacturer: Teledyne LeCroy } \\
\text { - Measuring range: } 0-700 \mathrm{~V}, \text { Accuracy: } \pm 2.0 \%\end{array}$ \\
\hline Current Transducer & $\begin{array}{l}\text { - Manufacturer: LEM } \\
\text { - Measuring range: } 0-19.2 \mathrm{Amps}, \text { Accuracy: } \pm 0.2 \%\end{array}$ \\
\hline
\end{tabular}


Table 2. Thermophysical properties of MPCM samples

\begin{tabular}{|c|c|c|c|c|c|c|c|}
\hline \multirow{2}{*}{$\begin{array}{c}\text { MPCM } \\
\text { Sample }\end{array}$} & \multicolumn{2}{|c|}{ Heating Cycle } & \multicolumn{2}{c|}{ Cooling Cycle } & \begin{tabular}{c} 
Subcooling \\
\cline { 2 - 8 }
\end{tabular} & $\begin{array}{c}\text { Particle Size } \\
(\mu \mathrm{m})\end{array}$ & $\begin{array}{c}\text { \% Shell } \\
\text { Material }\end{array}$ \\
\hline CT00 & 39.5 & 132 & 37.5 & 135 & 2.0 & $<10$ & 44 \\
\hline CT01 & 38.4 & 190 & 38.3 & 193 & 0.1 & $<10$ & 20 \\
\hline CT02 & 36.9 & 169 & 36.5 & 172 & 0.4 & $<10$ & 29 \\
\hline CT03 & 41.7 & 139 & 36.7 & 138 & 5.0 & $<10$ & 41 \\
\hline
\end{tabular}


Table 3. Thermophysical properties of MPCM slurries

\begin{tabular}{|c|c|c|c|c|c|}
\hline Fluids & $\begin{array}{c}\text { Mass Fraction } \\
(\mathrm{MF}) \text { of } \\
\text { MPCM }(\%)\end{array}$ & $\begin{array}{c}\text { Density } \\
\left(\mathrm{kg} / \mathrm{m}^{3}\right)\end{array}$ & $\begin{array}{c}\text { Viscosity } \\
(\mathrm{mPa}-\mathrm{s})\end{array}$ & $\begin{array}{c}\text { Effective } \\
\text { Thermal } \\
\text { Conductivity } \\
\left(\mathrm{W} / \mathrm{m}-{ }^{\circ} \mathrm{C}\right)^{1}\end{array}$ & $\begin{array}{c}\text { Effective } \\
\text { Latent Heat } \\
\text { of Fusion }^{(\mathrm{J} / \mathrm{g})^{2}}\end{array}$ \\
\hline Water & - & 992.3 & 0.67 & 0.626 & - \\
\hline MPCM (CT00) Slurry & 8.7 & 979.2 & 1.87 & 0.573 & 11.5 \\
\hline MPCM (CT01) Slurry & 11.0 & 983.2 & 1.73 & 0.559 & 20.9 \\
\hline MPCM (CT02) Slurry & 6.0 & 982.4 & 1.76 & 0.589 & 10.1 \\
\hline MPCM (CT03) Slurry & 6.5 & 975.7 & 1.99 & 0.586 & 9.0 \\
\hline
\end{tabular}

Note: 1. Calculated using Maxwell correlation [31].

2. It takes into account mass fraction of MPCM slurry. 
Table 4. Heat load-to-pumping power ratio, flow rate, pumping power consumption, and overall heat transfer coefficient in the demonstrations

\begin{tabular}{|c|c|c|c|c|c|}
\hline $\begin{array}{c}\text { Field } \\
\begin{array}{c}\text { Demonstration } \\
\text { No. }\end{array}\end{array}$ & Fluids & $\eta$ & $\begin{array}{c}\dot{V} \\
(1 / \mathrm{min})\end{array}$ & $\begin{array}{c}\dot{W}_{p} \\
(\mathrm{~W})\end{array}$ & $\begin{array}{c}U_{o} \\
\left(\mathrm{~kW} / \mathrm{m}^{2}{ }^{\circ} \mathrm{C}\right)\end{array}$ \\
\hline \multirow{2}{*}{1} & Water & 41.9 & 22.3 & 214.7 & 5.4 \\
\cline { 2 - 6 } & MPCMs (CT01) & 56.1 & 15.9 & 165.2 & 5.7 \\
\hline \multirow{2}{*}{2} & Water & 63.0 & 20.8 & 122.9 & 5.2 \\
\cline { 2 - 6 } & MPCMs (CT02) & 72.4 & 15.5 & 107.9 & 5.1 \\
\hline \multirow{2}{*}{3} & Water & 87.1 & 18.5 & 109.6 & 6.0 \\
\cline { 2 - 6 } & MPCMs (CT03) & 96.1 & 16.3 & 100.5 & 6.0 \\
\hline
\end{tabular}


Table 5. Ratio of heat load-to-pumping power ratio, flow rate ratio, pumping power ratio, and overall heat transfer coefficient ratio between MPCM slurry and water

\begin{tabular}{|c|c|c|c|c|}
\hline $\begin{array}{c}\text { Field Demonstration } \\
\text { No. }\end{array}$ & $\frac{\eta_{\text {MPCMs }}}{\eta_{\text {Water }}}$ & $\frac{\dot{V}_{\text {MPCMs }}}{\dot{V}_{\text {Water }}}$ & $\frac{\dot{W}_{p, M P C M s}}{\dot{W}_{p, \text { Water }}}$ & $\frac{U_{o, M P C M s}}{U_{o, \text { Water }}}$ \\
\hline 1: (MPCMs-CT01) & 1.34 & 0.71 & 0.77 & 1.06 \\
\hline 2: (MPCMs-CT02) & 1.15 & 0.75 & 0.88 & 0.98 \\
\hline 3: (MPCMs-CT03) & 1.10 & 0.88 & 0.92 & 1.00 \\
\hline
\end{tabular}


Table 6. Estimated life span of MPCM slurry

\begin{tabular}{|l|c|c|c|}
\hline & $\begin{array}{c}\text { Demonstration 1 } \\
\text { (CT01) }\end{array}$ & $\begin{array}{c}\text { Demonstration 2 } \\
\text { (CT02) }\end{array}$ & $\begin{array}{c}\text { Demonstration 3 } \\
\text { (CT03) }\end{array}$ \\
\hline $\begin{array}{l}\text { Total volume of heat transfer fluid } \\
\text { (HTF) in GSHP loop, } V_{t, G S H P}\end{array}$ & \multicolumn{3}{|c|}{22,8521} \\
\hline $\begin{array}{l}\text { Working flow rate of MPCM slurry } \\
\text { in GSHP loop, } \dot{V}_{G S H P}\end{array}$ & \multicolumn{2}{|c|}{$511 \mathrm{l} / \mathrm{min}$} \\
\hline $\begin{array}{l}\text { Time taken by HTF to circulate } \\
\text { through the whole GSHP loop, } \\
T_{\text {cycle }}\end{array}$ & \multicolumn{3}{|c|}{$44.7 \mathrm{~min} / \mathrm{cycle}$} \\
\hline Number of flow cycles, $N_{c y c l e}$ & 14,402 cycles & 38,805 cycles & 123,252 cycles \\
\hline $\begin{array}{l}\text { Estimated life span of MPCM } \\
\text { slurry, } L S_{M P C M s}\end{array}$ & 1.2 years & 3.3 years & 10.5 years \\
\hline
\end{tabular}

